\title{
Cycles of Creativity The story of one Mediation program
}

\section{Jennifer Beer}

\section{Abstract}

This essay summarizes reflections offered at the 2014 Edward Kennedy Institute Mediation Conference. Using as an example her community mediation program in Philadelphia, the author outlines the how the cycle of creativity affected the program (and the wider community mediation field) over time-starting with identifying a problem, then experimenting with exciting ideas, improvising, then formalizing, sustaining, and institutionalizing.

The author observes that both creativity and formalizing are essential, yet are necessarily in tension. After offering several ways mediators and programs can encourage creativity through comediation, mentoring, interacting with other fields, and risking improvisation, the essay concludes that the excitement of creative energy can propel a program and its offshoots for a long time afterward. However, creativity is ephemeral and at its heart, mediation is less about fostering creative approaches than about helping parties "be real." For the next creative cycle, mediators need to be "real" about the causes of community conflicts, and co-create pathways to conflict resolution that people in those communities find effective.

The 2014 Edward Kennedy Institute Conference theme of "Creative responses to conflict" prompted me to look again at my youthful experiences in an early community mediation program, with attention to the role of creativity — how it emerges, improvises, formalizes, finds ways to sustain and institutionalize, and appears again. The story may tell us more about the role of creativity in the formation of a new profession than it reveals about creativity in mediation and conflict resolution per se, so I visit that latter question briefly at the end.

For our purposes in this essay, "creativity" refers to the process of inventing a significant, original approach to something. Ideally the creators also have the craft skill to bring their idea into the real world. When a big- scale creative idea comes along at a receptive time, it can generate many offspring. The movement to apply "mediation" to whole new categories of disputes was one of those moments.

There are several commonly noted characteristics of how creativity unfolds that I will list briefly, then look at how they played out in a community mediation context:

- Although we tend to think of creativity as an intuitive and sudden insight - that Eureka! momentdurable ideas are most likely to emerge from sustained practice and study and experimentation.

- Within that field of knowledge, focusing on a limited problem, a puzzle, an idea, a specific situation also helps concentrate the creator'sattention. 
- Creativity often bubbles up at the margins and intersections, when someone deeply familiar with one area encounters practices and knowledge from an

- Two other factors encourage creativity.

- One is a loose, playful approach, as it helps loosen the mind from habit and judgmental voices.

- The other is collaborating and/or competing with other people, either of which can increase social motivation to create something or solve a problem. Teamwork also has the advantage of pulling and together a greater mix of knowledge and therefore the chance of productive cross-fertilization and more careful selection of winning ideas.

\section{Keywords}

Mediation program, cycles of creativity, improvising, formalizing, neighbourhood

\section{IDENTIFYING A PROBLEM}

In 1976, in my corner of the planet, Philadelphia, USA, a small Quaker program that dealt with fair housing and criminal justice problems in working class suburbs was looking to start a new project. They had been helping small communities deal with working class teens who were in trouble—runaways, young inmates in dangerous "reform schools," kids attacked by police dogs. This work brought their staff into the lowest level district justice courts, where they began to notice that conflicts between neighbours and families resulted in dissatisfaction all round - the parties went away angrier, and judges couldn't sort through the "he said, she said" facts nor enforce workable solutions.

The Quaker program took the first step in a creative process - they zeroed in on a particular problem - what approaches might take neighbour and family conflicts out of external authority, punishment-based courts, and help people gain control over their own conflicts and outcomes.

Community mediation, which was just coming over the horizon in the mid-70s, seemed an ideal answer. On the "reformist" side, the American Bar Association and several courts (including one in Philadelphia) had started a handful of pilot mediation programs, hoping to ease court caseloads. On the "community empowerment" side, Quakers and other activists were promoting mediation as a way to help communities to manage their conflicts without resorting to courts and police.

The Quaker staff attended a special one-time American Arbitration Association (AAA) mediation course and soon thereafter opened a county-wide Community Dispute Settlement program (Because it changed names several times, I will refer to it here by its current name, the Centre for Resolutions, or $\mathrm{C} 4 \mathrm{R})$. The mediation initiative started with the runaway cases they were already handling, as well as referrals from a few friendly district justices, hoping that they could invent a community peace-making resource, not just another agency that patched up individualgrievances. 


\section{IMPROVISING}

The next step in a creative process is making a promising idea into a physical and practical reality - in C4R's case, developing the "how-to" of mediating. This high energy phase is a kind of "improve," where one gains knowledge and experience through trial and error, with few protocols or rules constraining that experiment.

As only a few outside mediation resources were available, the new program mostly invented its own mediation techniques by trying out ideas and seeing what worked. In this way they were following Rule \#1 in theatre improve: "Say "YES" to the reality you find, and then add something of value to it. Each of those early mediations was an adventure in trial and error (and several ended up as classic role plays!).

They tried holding family mediations at the parents' house, and found that the teens shut down — which led the program to seek out churches and other free community spaces. The mediators practiced summarizing, and speaking to people's interests.

They learned what to ask disputing parties beforehand: Do you have someone to babysit your children? Who else should be there? Are any weapons or threats of violence involved? Mediators who aspired to empowerment (an idealistic term we used in the pre-transformative days to mean "community and personal self- determination") tended to lean back and let people vent. This sometimes led to yelling matches that ended the mediation. On the other hand, mediators who worried about control or came from a legal background, sometimes pressed people into reaching agreements too soon, which could also backfire. The frequent updates in training materials during those early years show C4R gradually working out strategies for typical mediation problems: when and how to intervene when name-calling starts; what to do when someone walks out; how to word an agreement for clarity but also in language that feels natural to the participants; how to generate a topic list using neutral language; uses for separate meetings; as well as dozens of insights and tweaks.

How many disputing parties suffered as we practiced on them? Some, no doubt; though they always had the option of the local court if they didn't like the mediation outcome. While our intentions were earnest, awareness of subjects' rights was not the concern it is today.

It was an exciting and fun time. What I remember most as an intern was our two or three-hour staff meetings, reviewing the latest mediations and intake cases, arguing, laughing, spontaneously roleplaying. We felt that we were honing a valuable idea, and were deeply engaged in its creation.

\section{FORMALIZING}

Successful creative ideas eventually settle into fixed forms, just as a jazz riff eventually becomes a composition, or a comic sketch becomes a comedian's set performance piece.

C4R's improvements became more about formalizing, much of which literally involved forms and paper—forms for record keeping, training materials, forms for mediator evaluation, forms for writing 
agreements—as well as establishing set practices.

Even as we continued to experiment with methods, the basic framework of C4R's intake and mediations was already well in place by the time I arrived 4 years into the program. Among these were the use of 2 volunteer mediators, intake with staff talking to each party in advance by phone (with minimal recordkeeping), the session sequence from Opening Statement to Agreement Writing and Closing, as well as the program's guiding values of empowerment, respect, and promoting nonviolence. The processes and skills C4R practices today are assuredly more varied and nuanced, but those initial elements still form the core scaffolding.

In another formalizing move, the program started publishing an inexpensive Mediator's Handbook before such training materials were widely available. Early on, we updated it every year. Preparing each new edition pushed us to be creative and think deeply again, even as we were trying to formalize the material. The book spread C4R's basic methods, values, and terminology far beyond our small program. The complete rewrite published in 2012 took several years of intense examination of our methods and experimentation to clarify or change long-time ways of mediating that didn't seem to work as well as we liked. I found this process required

Another aspect of formalizing was participating in the professionalization of the field. The burgeoning number of programs, practitioners, and researchers in and beyond Philadelphia meant more collaborative work, more conferences, more sharing of ideas, and therefore fewer home-grown innovations. The field was concerned with developing formalities-- certification, legal protections, training requirements, protocols, ethics standards-these and many other structures, ostensibly to reassure clients and governments that people were getting quality mediation, but more importantly to establish mediation as a profession as different groups were vying for primacy in the emerging field Formalization was partly a way to spread mediation ideas and practice more widely, partly about attaining credibility, recognition, and control by outlining who should mediate and how.

\section{CREATIVITY CYCLES The progression of mediation from idea to common practice}

IDENTIFYING A PROBLEM — crowded courts, disempowered communities

IMPROVISING — mediation as a movement, idealism, experiments, rapid expansion, grant money

FORMALIZING - codifying methods, starting organizations and programs, developing an academic field of study.

SUSTAINING, as a business, as a profession - forming professional associations, becoming self-sustaining, establishing private practices with new mediation markets prompting different "schools" of mediation practice, academic degrees in the subject.

INSTITUTIONALIZING - Mediation anchored in larger systems: gradual normalization of mediation as an option inside and outside the justice system, peer mediation in schools, mandatory mediation, certification, mediation as academic discipline.

RE-CREATING — ideals and ideas championed by the early movement are recreated in other forms, such as circle 
processes, ombuds work, restorative justice, community organizing, and the creative cycle begins again

\section{SUSTAINING-as a business, as a profession}

Movement ideals and creativity are invigorating, but programs need cash flows. In 1982, C4R was spun off to become independent from its Quaker founders. Inspired by the Dorchester program in Boston, it moved to a storefront in a poor neighbourhood. The new staff took the program design and mediation model as a given. They focused their efforts on growing the program—spending their time writing grants, doing outreach to persuade police and courts and agencies to use mediation services. Like many other mediation programs, they turned to trainings as a major source of income, not just as a way to prepare program volunteers. They worked with schools (from elementary age through college) institute peer mediation programs, and trained staff of non-profit agencies.

Storefront C4R's' idealism was challenged as we realized that neither the poor nor the well-off communities in our region were motivated to seek out mediation services. Even individuals who had experienced a successful mediation rarely used it again or recommended it to others. With no foot traffic coming into the storefront, and direct involvement in larger community issues not happening either, after about four years, C4R made a business decision to move thirty minutes away to the county seat near other social service agencies and the county courts. Eventually they renovated an old carriage house across the parking lot from the police station and borough offices - separate but close by.

It is perhaps telling that in the 90s the word "Community" was dropped from C4R's name. The new one, "Center for Resolutions," allowed the organization to move beyond mediation, and to serve a wider range of clientele, in particular running a county-wide program of community panels for first time juvenile defenders, which, along with training programs, and donations from municipalities has become the organization's main financial support.

This move away from community disputes was part of a larger trend across the United States, as the government and social service grants that funded the initial movement turned to newer trends. Mediation organizations (as well as individual mediators) sought out disputes that could provide income, and built connections with referral institutions that could provide a steady supply of mediatable disputes.

Barking dogs' cases gave way to divorce mediations; resolving tenant/landlord disputes and to lawyer-mediators settling insurance claims. JAMS and other mediation firms hired retired judges to attract high value commercial clients. Trainers like myself travelled far distances to spread our ideas and to earn a living. Entrepreneurial (creative!) moves spread mediation into new areas such as construction, environment, international business, or peace-building. Mediators adapted the process to suit their clients' expectations (which meant aligning to some extent with the methods, goals, and culture of commercial litigation, labour negotiations, Human Resource departments, family courts and marital therapy).

By the early 1990s, mediation had become an established profession as well as a business and an academic discipline. Ironically, those moves outward in search of financial stability and new opportunities return us back to the original problem $\mathrm{C} 4 \mathrm{R}$ set out to address almost four decades ago: how to respectfully and effectively mediate the disputes of poorer members of society who don't bring money 
into the pipeline.

That said, C4R and other community programs have been reluctant to abandon their dedication to mediating neighbour and family disputes, including custody cases. For several decades C4R asked for donations but charged no participant fees. Today it charges a modest fee for mediations, waiving it when needed (This is partly for economic reasons, partly because sometimes participants take mediation more seriously when they are paying for the service.) Local judges and police continue to refer cases, having learned that mediation works best for some small-scale conflicts.

In line with the commitment to resolving community disputes that involve ongoing relationships, C4R continues to use "facilitative" (with degrees of "transformative") mediation approaches that differ from those used by "professional" mediators, some of whom regard volunteer or non-lawyer mediation methods as quaintly naive or even as unprofessional, while we in turn wonder whether mediation that downplays self- determination should be called mediation at all! (Though as long as we keep talking, I believe that mutual challenge is a productive tension.)

C4R's annual number of mediations and number of volunteer mediators has held steady over the 35-year period. As part of our discussion about creativity, we need to ask why the organization has invested energy into improvement of quality training and mediating, but virtually none towards innovation. One reason is the small staff and small budget-serving a defined niche takes less time and effort. More fundamentally, we have already seen that creativity is more likely to occur with a new program initiatives or a new clientele. For example, the mediation program could expand into public meeting facilitation, into conflict coaching, or into community organizing. They are taking on a few zoning disputes and elder mediations lately, that may bring another creative burst. I often wonder what community mediations would look like if instead of promoting our mediation services, we took a market research approach, heading for neighbourhoods dealing with much conflict, and worked with them to develop a home-grown approach that neighbours could run themselves, one that would feel culturally "natural" and capitalize on their existing network of relationships.

\section{INSTITUTIONALIZING}

Slowly but increasingly, we see mediation and other related methods being instituted within schools, companies, agencies, and court bureaucracies. This is both a hope fulfilled and a regret.

In the Philadelphia area, as elsewhere, when the mediation movement gained steam, tensions arose over how to connect mediation programs with the judicial system, as the most reliable source of case referrals. Which disputes would court or police willingly send to C4R? Which disputes could only be handled by lawyer-mediators? How much information did C4R need to tell the judges about the referred cases we handled?

Although it had been explicitly invented as an alternative to litigation, it turned out that the public had no interest in calling C4R for a mediation instead of filing a complaint with the police or the court. To gain access to mediation cases, C4R has carefully walked a tightrope-maintaining a cordial yet 
independent relationship with district justices and county courts. By the 2000s, C4R was receiving an increasing number of mandated cases, and receiving small payments from the courts for handling custody disputes.

C4R's other intersection with entrenched institutions is with schools. Teaching mediation and conflict resolution to children and teens has been (and still is) satisfying and useful. Making space for those new ways of handling conflicts means jostling the mindset of hierarchical school eco-systems-for example, by choosing mediators from among informal peer leaders instead of honor students, or by setting up mediation options for parents and teachers so that mediation is seen as something grown-ups also use - and this is always challenging.

\section{TENSION BETWEEN CREATING AND FORMALIZING}

There is a necessary tension between creativity and formalization. Formal structures both limit and inspire creativity -just as the type of paints an artist uses, or the range and timbre of a musician's instrument, constrain their artistic choices but that focus may also deepen their skill and intuition. Institutions need to manage conflict outcomes closely and to sustain their power relations. They develop systems which freeze out innovation in some areas, encourage learning in others - In the mediation field we deal with our own institutionalization through protocols, required training, professional certification and ethics standards, assessment instruments, manuals, etc., and with the ways our referral sources institutionalize how we mediate the disputes they send us. Such forms by their nature rein in the freewheeling experimentation needed for substantive creativity.

To be harsher about it, from a Foucauldian perspective, new practices embed themselves into new disciplines of mind, body, and relationships. Over time these new ways of doing and being will be co-opted, contained, and transformed by society's powerful controlling processes. This is the price novel initiatives pay for achieving integration into society.

Creativity innovates. Formalization makes it possible to sustain and spread those promising ideas and methods. Each side attacks the other - creative people rebel against form, managers and organizations press to keep the momentum going by establishing rules, procedures, customary practices, coordination, laws. Yet creative people do better faced with defined problems and structural limits. They also want their ideas to take root and replicate. Organizations need innovations to keep their systems responsive to current needs. Neither can thrive without the other.

\section{RE-CREATING}

With any type of collective endeavour, ways of doing things may become entrenched and therefore brittle, or at least unexciting. Innovative approaches eventually line up within the magnetic fields of powerful systems. Techniques can become disconnected from the adaptive, creative wisdom that initially shaped them.

So what happened to creativity? Like water, creativity finds other channels. Today's mediators are 
expanding their practice into new areas, creating new venues, and adapting their processes to fit. Mediation methods and ideas have already been borrowed, re-invented, composted into newer trends such as circle processes, peace- building, healing circles, restorative practices, community conferencing. The fields of peace-building, reconciliation, and ADR have travelled far beyond the boundaries of what the movement of the 70s and 80s initially defined as "mediation."

This morphing into many forms and many venues is a sign that mediation processes are fundamentally solid, that they are based on anthropological and psychological understandings of how humans behave in conflict and what works to edge parties away from escalation and towards a calmer future.

Re-invention and re-creation is vital for us as well as for the world we work with. Like new sets of leaves on an old tree, "every generation has to feel like they were the first to care about this problem, the first to come up with these brilliant ideas," my mentor from the Quaker project used to say with a rueful shake of his 61-year old head. Mediation sessions are structured with the same truth in mind: we humans understand things better when we experience them directly. And, whether it is a mediated agreement or a developing a mediation process, we are more committed to things we invent ourselves.

\section{SPARKING NEW CREATIVITY}

In a way, being in creative flow is a lot like being in love. You can't command it to happen. You can't control it. It's exhilarating and absorbing, but you can't keep hold of it.

However, there are some things mediators and mediation organizations can do to plow the ground, to keep yourself open to creative insights.

- Co-create with your parties. Our imaginations are limited by culture, habit, education, and personality. Working with participants to design an effective mediation means learning how they make sense of the world, what their cultural practices and expectations are about resolving conflicts and repairing relationships.

- Encourage yourself and your colleagues to improvise and to discuss the results.

- Co-mediate. A lot of mediators work solo, as it pays better and is less hassle. However, working as a mediation team lets you experience different styles and approaches first hand, and to get feedback from other skilled mediators.

- Take the time to evaluate right after you mediate. Creativity happens when you pay conscious attention.

- Seek out opportunities to work on projects with people from diverse communities, and with professionals from different fields, who have not had much contact with formal conflict resolution or mediation.

- Mentor, with openness towards what newer mediators can teach you.

- And, Read, read, read! 


\section{GETTING REAL. IS CREATIVITY OVER-RATED?}

Lest we end with the perception that mediation is in need of a new burst of creativity (or with valid complaints that I have overlooked many creative elements in the mediation field), let's take a step back to question whether creativity is essential to conflict resolution in the first place. We often promote mediation as giving people the opportunity to tailor their own custom solutions, to re-start a relationship on their own terms.

Honestly, how many mediation parties come up with truly creative or unique terms of agreement? My guess is not very often.

Creative solutions are risky. They can be harder to sell to a court or put into contract form. The market and the courts have already developed effective and customary contracts and remedies for worldliest problems. The more common the type of dispute, the more difficult it is to invent smart solutions that haven't been tried before.

Second, parties are often eager to be done with the mediation, done with the conflict. It takes time to explore a problem thoroughly enough for creative solutions to surface and be vetted. Quickness generally leads to customary results. People return to social norms of fairness and politeness. For all these reasons, parties' terms of agreement are usually quite predictable. Creativity does not seem that relevant. It may even get in the way.

Luckily for us, mediation is not about helping people get creative, though that is an occasional exciting by-product. Mediation is about getting real. It requires attention to the NOW. We deploy our mediator toolkits to help parties to reach a larger shared understanding, a wider view of reality. What does their situation look like from the other side? What outcomes are possible, what is good-enough or fairenough, what agreement is likely to hold up? Doing this well is difficult and rewarding-whether or not the mediator's techniques are inventive or a session's outcomes are creative.

In conclusion, the energy of deep creativity is exciting. It can propel new initiatives and organizations, rippling outward for a long time afterward. However, there's no need to fret about whether mediators are creative enough. Instead, we can keep our attention on what is real, what is needed, and on staying open to new experiences and information. Then, when, in the course of our work, an aha! idea strikes, we can be ready for it, dare to try it out, changing the reality of conflicts we encounter and the new realities we help people create for themselves.

In the larger perspective, various 20th century "technologies" of conflict resolution, negotiation, and peacemaking have successfully spread essential ideas such as focusing on interests, making room for all voices and then listening to them, acknowledging pain, recognizing divergent perspectives, and consensual decision- making. Mediation has been a visible leader of that cultural change. In terms of providing a valuable service at the community level, however, most people embroiled in local and family conflicts do not have access to mediators, nor do they seem to want them. How can mediators co-create 
pathways to conflict resolution that their communities actually want to use and can mostly carry out themselves?

A creative response requires deep learning about the reality in front of us, starting with the disputing parties themselves--what feels right and needed to them and to those nearby? As we see in C4R's trajectory, it is easier to focus on solving individual conflicts. This time round, we must consistently recognize the larger, structural context, to develop conflict resolution initiatives that directly address those political, cultural, and economic pressures that foist conflicts onto our poorer communities.

I am hopeful mediators will generate a new creative cycle, taking a fresh angle on the perennial challenges of building local justice. Collaborate! Cross-pollinate! Improvise! Think big! Our communities need your knowledgeable and creative attention.

Dr. Jennifer Beer runs her own consulting business in Philadelphia, USA. She has mediated conflicts and facilitated meetings in communities and non-profit organizations for 3 decades. Today, Jenny combines her mediation experience and her Ph.D. in cultural anthropology to teach negotiation at Wharton (University of Pennsylvania) and at ALBA business school in Athens, Greece. She offers workshops in mediation, conflict assessment, training design, and cross-cultural communication.

The newest edition of her well-used Mediator's Handbook, published with her co- author two years ago, has been in print since 1982. She also authored Peacemaking in Your Neighbourhood, a study of the early years of community mediation in the Philadelphia area. 